\title{
Memory loss
}

\author{
Five new things
}

Ferenc Deak, MD, PhD; Nidhi Kapoor, MD; Calin Prodan, MD; Linda A. Hershey, MD, PhD

\begin{abstract}
Purpose of review: Memory loss can be due to a wide variety of causes. We provide new information about the biology of common genetic and acquired causes of memory loss in older adults. Recent findings: New data are available about the genetics of Alzheimer disease (AD), dementia with Lewy bodies (DLB), and frontotemporal dementia. Amyloid PET, FDG-PET, and MRI have improved our understanding of how mild cognitive impairment evolves to AD. Several studies have shown links between concussion and chronic traumatic encephalopathy. Healthy eating and regular exercise have been demonstrated to slow cognitive decline in older adults. Randomized trials continue to show benefits for cholinesterase inhibitors and memantine in patients with $A D$ and DLB. Summary: New causes of memory loss are still being identified. More sophisticated diagnostic tools have improved our ability to make earlier diagnoses in older adults with memory loss. Neurol Clin Pract 2016;6:523-529
\end{abstract}

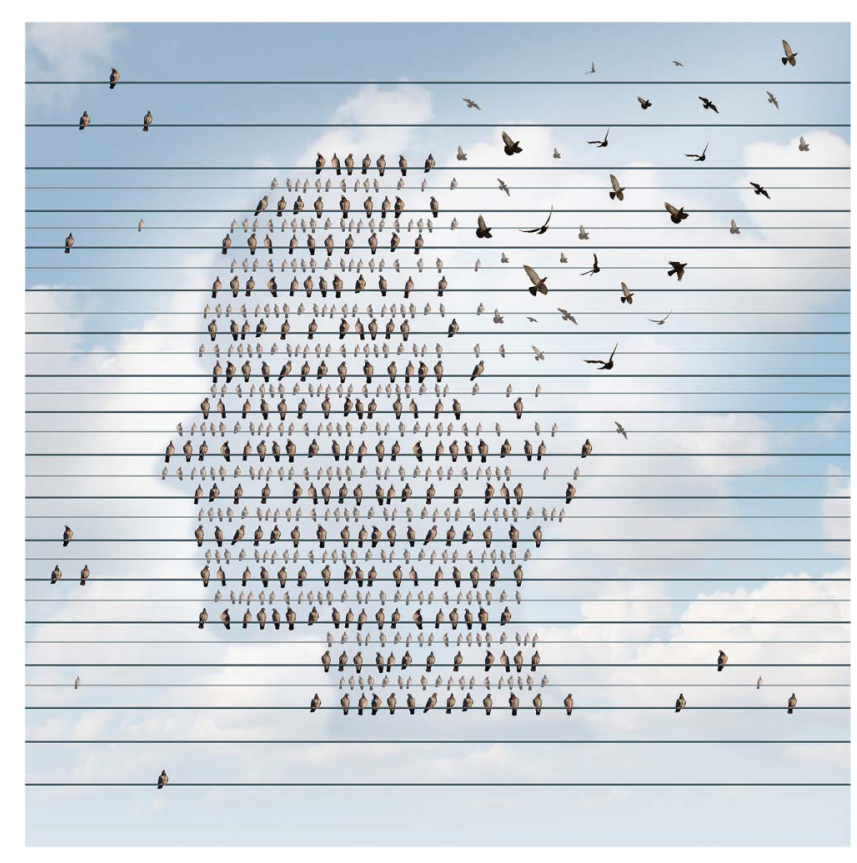

ecent large neuropathologic studies have shown that Alzheimer disease (AD) is still
the most common of the chronic neurodegenerative memory disorders, but it is of-
ten associated with several comorbid histologic findings, such as cortical Lewy bod-
ies, hippocampal sclerosis, and microinfarcts.

\section{Amyloid hypothesis and the genetics of AD}

While it is well-accepted that memory loss and other cognitive impairments in $\mathrm{AD}$ are the result of dysfunction in neuronal networks and synapses, the exact molecular and pathologic steps generating the clinical symptoms of $\mathrm{AD}$ remain an issue of some debate. Some have argued that $\beta$-amyloid $(A \beta)$ is a necessary but insufficient factor to explain the etiology of $A D$, arguing that $A \beta$ aggregations in the brain and decreased $A \beta$ levels in spinal fluid are detectable 15-20 years before the clinical symptoms of $\mathrm{AD}^{2}$ Contradicting this view are recent findings from the Alzheimer's Disease Neuroimaging Initiative (ADNI), which demonstrated that decreases in CSF A $\beta$ levels are often not apparent until after there is a noticeable decline in cognitive function, a decline in metabolic activity on FDG-PET, and

University of Oklahoma Health Sciences Center, Oklahoma City.

Funding information and disclosures are provided at the end of the article. Full disclosure form information provided by the authors is available with the full text of this article at Neurology.org/cp.

Correspondence to: linda-hershey@ouhsc.edu 


\section{Amyloid PET had a higher sensitivity for identifying $A D$ (89.5\% average between raters) compared to FDG-PET (77.5\%).}

a decline in MRI volume in patients who are at risk for AD. ${ }^{3}$ Nevertheless, a European memory clinic study of 73 patients with mild cognitive impairment (MCI) found support for the amyloid hypothesis, since they found more rapid conversion from MCI to AD among patients with MCI whose diagnostic tests showed 3 characteristic findings: amyloid PET scans with frontal lobe amyloid deposits, FDG-PET scans with cingulate hypometabolism, and MRI scans with hippocampal atrophy. ${ }^{4}$

The APOE \&4 allele is a common risk factor for late-onset $\mathrm{AD}$. In another European study of 147 amnestic patients with $\mathrm{MCI}$, those most likely to transition to AD over a 2-year period were those who had lower spinal fluid levels of $A \beta(A \beta 42)$, lower parietal cortex thickness on MRI, poorer visual and spatial recognition on neuropsychological tests, and the presence of at least one $A P O E \varepsilon 4$ allele. ${ }^{5}$ Having at least one $\varepsilon 4$ allele lowers the age for developing $\mathrm{AD}$ in the late-onset cohort of patients with $\mathrm{AD}$. A case-control series of patients with $\mathrm{AD}$ and controls from the United States, Norway, the Netherlands, and Germany was studied to find other genetic markers for AD. ${ }^{6} \mathrm{~A}$ rare missense mutation called TREM2 was found to confer significant risk of $\mathrm{AD}$ among patients in Iceland (odds ratio 2.92). The encoded protein functions in the immune response system and may be involved in chronic inflammation. The mutation had a frequency of $0.46 \%$ among older controls, and the carriers of the mutation had poorer cognitive function than noncarriers, even though they did not have dementia.

Most early-onset $\mathrm{AD}$ cases (onset before age 65 years) with autosomal dominant inheritance have characteristic mutations either in the amyloid precursor protein (APP) gene or in the genes for its processing secretases, presenilin-1 or presenilin-2. A remarkable case of early-onset $\mathrm{AD}$ with a recessive APP A673V point mutation has been described. ${ }^{7}$ The patient had memory loss starting at age 36 years, followed by progressive memory decline, reaching an IQ of 47 and Mini-Mental State Examination of $17 / 30$ by age 44 . A protective variant of the same amino residue of APP (A673T) was subsequently reported by an Icelandic group in participants without $\mathrm{AD} .{ }^{8}$ In these participants, there is markedly less $A \beta$ production due to slower proteolysis by the $\beta$-site APP cleaving enzyme 1, or BACE1. Indeed, inhibition of BACE1 is one of the leading targets to develop more effective $\mathrm{AD}$ treatments. ${ }^{9}$ The recent novel genetic and therapeutic advances in the fields of memory loss and cognitive impairment are summarized in table 1.

\section{Amyloid $\mathrm{PET}$ imaging in $\mathrm{MCl}$ and $\mathrm{MRI}$ for subtyping $\mathrm{AD}$}

When memory loss is a prominent feature of MCI, we suspect that the patient has amnestic MCI (aMCI), or prodromal AD. Nevertheless, there are some situations where it is difficult to know whether we are dealing with early stages of $\mathrm{AD}$, dementia with Lewy bodies (DLB), frontotemporal dementia (FTD), or normal aging. Amyloid PET and FDG-PET are both useful tools in this situation, since they show similar accuracy in discriminating AD and FTD. ${ }^{10}$ Amyloid PET had a higher sensitivity for identifying AD (89.5\% average between raters) compared to FDG-PET (77.5\%). The amyloid model of AD predicts that a positive amyloid PET scan should be seen in an aMCI phase of the disease and should precede synaptic dysfunction on FDG-PET and hippocampal atrophy on MRI. ${ }^{4}$ When this model was tested examining by 73 patients with aMCI, 29 eventually progressed to dementia, $74 \%$ following the predicted sequence described above. Jack et al. ${ }^{11}$ recently used serial amyloid PET and MRI in 1,246 cognitively normal individuals and found that worsening of memory and reduction of hippocampal volume over time preceded amyloid accumulation on amyloid PET in several older individuals, arguing that 
Table 1 Major hallmarks of chronic neurodegenerative disorders with memory loss, including recent genetic associations as possible therapeutic targets

\begin{tabular}{|c|c|c|c|c|c|c|}
\hline Disorder & $\begin{array}{l}\text { Age at } \\
\text { onset, } \\
y\end{array}$ & Pathology & Classical genes & $\begin{array}{l}\text { Recent genetic } \\
\text { association }\end{array}$ & $\begin{array}{l}\text { Current } \\
\text { therapeutic } \\
\text { targets }\end{array}$ & $\begin{array}{l}\text { Prevalence } \\
\text { (cases per } \\
100,000 \text { ) }\end{array}$ \\
\hline Early-onset AD & $35-65$ & Plaques, tangles & APP, PSEN1, PSEN2 & & $\begin{array}{l}\text { Cholinesterase, } \\
\text { inhibitors, NMDA } \\
\text { antagonists }\end{array}$ & 40 \\
\hline Late-onset $A D$ & $65+$ & Plaques, tangles & APOE $\varepsilon 4$, MAPT Tau & $\begin{array}{l}\text { CLU, PICALM, SORL1, } \\
\text { BIN1, LRP1, LRP6, CR1, } \\
\text { CD33, MS4A6A, } \\
\text { BRCA1, TREM2 }\end{array}$ & $\begin{array}{l}\text { Cholinesterase } \\
\text { inhibitors, NMDA } \\
\text { antagonists }\end{array}$ & 1,200 \\
\hline DLB & $60+$ & Lewy bodies & SNCA $\alpha$-synuclein & PARK, LRRK2 & $\begin{array}{l}\text { Cholinesterase } \\
\text { inhibitors, NMDA } \\
\text { antagonists }\end{array}$ & 52 \\
\hline FTD & $50+$ & $\begin{array}{l}\text { Pick bodies }+ \text {, } \\
\text { balloon neurons }\end{array}$ & $\begin{array}{l}\text { MAPT Tau, TDP-43, } \\
\text { FUS }\end{array}$ & $\begin{array}{l}\text { TARDBP, C9orf72, FUS, } \\
\text { PGRN }\end{array}$ & & 14 \\
\hline $\mathrm{VaD}$ & $55+$ & $\begin{array}{l}\text { Large stroke, } \\
\text { multiple infarcts, } \\
\text { or extensive white } \\
\text { matter changes }\end{array}$ & APOE $\varepsilon 4$, MMP2 & $\begin{array}{l}\text { NOTCH3 CADASIL, } \\
\text { CST3, ITM2, HTRA1 }\end{array}$ & $\begin{array}{l}\text { Antihypertensive } \\
\text { and antiplatelet } \\
\text { drugs }\end{array}$ & 850 \\
\hline
\end{tabular}

Abbreviations: $\mathrm{AD}=$ Alzheimer disease; $\mathrm{APP}=$ amyloid precursor protein; $\mathrm{BIN1}=$ bridging integrator 1 ; $\mathrm{BRCA} 1=$ breast cancer gene 1; C9orf72 = chromosome 9 open reading frame 72; CADASIL = cerebral autosomal dominant arteriopathy with subcortical infarcts and leukoencephalopathy; CLU = clusterin; CR1 = complement receptor type 1; CST3 = cystatin 3; DLB = dementia with Lewy bodies; FTD = frontotemporal dementia; FUS = FUS RNA binding protein; ITM2B = integral membrane protein 2B; LRP1 = low-density lipoprotein receptor-related protein 1; LRRK2 = leucine-rich repeat kinase 2; MAPT = microtubule-associated protein tau; MMP = matrix metalloproteinase; MS4A6A = membrane-spanning 4-domains, subfamily A, member 6A; PARK = Parkinson disease associated genes; PICALM = phosphatidylinositol binding clathrin assembly protein; PSEN1 = presenilin 1; PSEN2 = presenilin 2; SNCA = synuclein- $\alpha$; SORL1 = sortilin-related receptor A; TDP-43 = TAR-DNA-binding protein; TREM2 = triggering receptor expressed on myeloid cells $2 ; \mathrm{VaD}=$ vascular dementia.

memory decline in several older individuals was due to the aging process itself, and not to the accumulation of $A \beta$ deposits in the brain. This fits with recent findings of the ADNI investigators, who found many patients who experienced cognitive decline before changes occurred in CSF $A \beta .^{3}$

These studies emphasize that AD exhibits considerable clinical, anatomic, and pathologic heterogeneity. These differences are fairly noticeable in the early stages, but they become less apparent as the disease progresses. In a recent assessment of 152 patients with mild AD using high-resolution T1-weighted volumetric MRI scans, 3 subsets of patients with AD were described based on anatomic and neuropsychological differences. ${ }^{12}$ These anatomic subtypes were established by clustering the patients based on whether the cortical atrophy was diffuse, parietal-dominant, or medial temporal-dominant. The characteristics of the patients are described in table 2. The patients with parietal-dominant $\mathrm{AD}$ were younger at onset than the other 2 subtypes, and they had more problems with attention, visuospatial function, and executive abilities on neuropsychological tests. ${ }^{12}$ The European ADNI study also documented more thinning of the parietal cortex among patients with prodromal AD who had poor visual and spatial recognition abilities. ${ }^{5}$ These new anatomic findings on MRI are helpful to clinicians who are counseling patients about their memory deficits and about other cognitive problems that are associated with $\mathrm{MCI}$ and $\mathrm{AD}$.

\section{Mild traumatic brain injury as a risk factor for $A D$ and chronic traumatic encephalopathy}

Several studies have shown that mild traumatic brain injury (TBI) is a major risk factor for the development of $\mathrm{AD}$ in later life, particularly in conjunction with at least 1 APOE $\varepsilon 4$ allele, 


\section{Several studies have shown that mild TBI is a major risk factor for the development of $A D$ in later life.}

although the time interval from trauma to dementia was unclear in these early studies. ${ }^{13,14}$ More recently published data have highlighted the temporal relationship between TBI and subsequent dementia, with a $60 \%$ increased risk of dementia over 9 years in older veterans with TBI after competing risks were accounted for. ${ }^{15} \mathrm{TBI}$ cases of all degrees of severity were included in this study, so there is still a question about whether mild TBI is linked to an increased risk of $\mathrm{AD}$.

There is an increased recognition of the role played by minor repetitive brain injuries in the development of behavioral changes and cognitive impairment in patients who have chronic traumatic encephalopathy (CTE), a neurodegenerative disease that shares several clinical and neuropathologic features with AD. ${ }^{16-18}$ Patients with $\mathrm{AD}$ can have memory loss, mood swings, and agitation, just as patients with CTE can have those same symptoms. CTE is defined pathologically by the abnormal accumulation of the tau protein in a pattern that is different from other tauopathies, such as AD and FTD. When brains of patients with CTE show A $\beta$ plaques in addition to deposits of tau protein, the patients are more likely to be older at symptom onset and have at least $1 A P O E \varepsilon 4$ allele. ${ }^{18}$ One recent MRI study revealed smaller hippocampal volumes in collegiate players with and without concussion, compared to agematched individuals who did not play football, ${ }^{19}$ providing support for an influence of mild repetitive brain injury on brain structures that are involved in memory processing.

\section{Healthy eating and regular exercise to prevent dementia}

Lifestyle factors appear to be effective in reducing the risk of dementia. In a large longitudinal study of 716 older adults without dementia who were followed over about 4 years, 71 eventually developed signs of $\mathrm{AD} .{ }^{20}$ In a Cox proportional hazard model that adjusted for age, sex, and educational level, a higher level of total daily physical activity was associated with a reduced incident rate of $\mathrm{AD}$ (hazard ratio 0.477). The association persisted after adjustment for depressive symptoms, chronic health conditions, and $A P O E \& 4$ status. At the end of the 3 -year Leukoaraiosis and Disability study, 90 of the 639 participants had developed dementia. ${ }^{21}$ Physical activity (at least 30 minutes of activity on at least 3 days per week) significantly reduced the risk of cognitive impairment, especially vascular dementia. In a large, racially diverse cohort of 876 older adults (the Northern Manhattan Study), there was more likely to be decline at 5 years in semantic memory and executive function if there were low levels of leisure time physical activity. ${ }^{22}$

Table 2 Anatomical subtypes of Alzheimer disease (described by Noh et al. ${ }^{12}$ )

\begin{tabular}{|c|c|c|c|c|c|c|}
\hline & Subtypes & Brain atrophy & Age at onset, y & Sexual distribution & $\begin{array}{l}\text { Mean } \\
\text { cortical } \\
\text { thickness }\end{array}$ & $\begin{array}{l}\text { Association } \\
\text { with APOE } \& 4\end{array}$ \\
\hline 1 & Diffuse & Generalized & Oldest, $X=72.2$ & Predominantly female (66.7\%) & Lowest & Intermediate \\
\hline 2 & $\begin{array}{l}\text { Medial } \\
\text { temporal }\end{array}$ & $\begin{array}{l}\text { Medial temporal/ } \\
\text { cingulate-dominant }\end{array}$ & Intermediate, $X=69.8$ & Predominantly female (73.1\%) & Highest & Highest \\
\hline 3 & Parietal & Parietal dominant & Youngest, $X=57.1$ & Equal male to female ratio & Intermediate & Lowest \\
\hline
\end{tabular}


Diet can also influence the rate of cognitive decline. In Finland, there was recently a randomized controlled trial of 1,260 participants, designed to test the hypothesis that healthy eating, exercise, and cognitive training could prevent cognitive decline among those who were at risk for dementia. ${ }^{23}$ Participants were 60-77 years of age and had a dementia risk score of 6 points or more; cognition was slightly lower than expected for age. After 2 years, there was a significant change in the $Z$ score of a comprehensive neuropsychology battery of tests, with the intervention group doing better than the control group. Adverse effects were more common among the intervention group (7\%), compared to controls $(1 \%)$, with the most common complaint being musculoskeletal pain (5\%). Another large clinical study has offered support for the idea that healthy eating can reduce the risk of cognitive decline. ${ }^{24}$ In 2 large $(n=27,860)$ international clinical trials of antihypertensive agents, diet quality was assessed using the modified Alternative Healthy Eating Index. After 56 months of follow-up, 4,699 cases of cognitive decline occurred. The risk of decline was less in those with the healthiest diets (more vegetables, fruits, nuts, soy proteins, whole grains, and fish, and less consumption of red meat).

\section{Cholinesterase inhibitors for $A D$ and memantine for DLB and FTD}

Several cholinesterase inhibitors (donepezil, rivastigmine, and galantamine) have been shown to be effective in treating the cognitive and behavioral changes that are associated with mild to moderate AD. ${ }^{25}$

\section{Memory loss: Five new things}

- There are new genes that both cause and protect against $A D$. The protective gene variant may lead to new treatments for $A D$.

- Amyloid PET and MRI are both helpful tools for identifying which patients with $\mathrm{MCl}$ will most likely go on to develop $A D$.

- Mild TBls appear to be risk factors for both $A D$ and CTE. These 2 conditions can overlap in individuals who are older and have at least 1 APOE $\varepsilon 4$ allele.

- Lifestyle factors appear to delay the expression of the late-life $A D$ genotype in older adults. Daily physical activity can reduce the incidence rate of $A D$ and vascular dementia, even after adjusting for the APOE $\varepsilon 4$ genotype.

- Donepezil is useful in treating mild to moderate $A D$ and $D L B$; it can prevent nursing home placement in patients with moderate to severe AD. Memantine is useful in managing cognitive and behavioral symptoms of $A D$ and $D L B$.

Memantine is an antagonist of glutaminergic neurotransmission at

NMDA receptors, and previous studies had shown that patients with DLB had overactivity of CNS glutamate. ${ }^{26}$ This was the rationale for the design of a randomized, double-blind clinical trial in 75 patients with mild to moderate DLB who showed significant improvement in global clinical status and behavioral symptoms with memantine. These benefits were seen in a population of patients with DLB who had not yet been treated with cholinesterase inhibitors (since there is a cholinergic deficiency in this disease, most patients with DLB respond favorably to drugs like donepezil or rivastigmine). Memantine was also assessed in a randomized trial of 81 patients with FTD who either had the behavioral or the semantic variant of FTD. ${ }^{27}$ The authors found no cognitive or behavioral benefit of memantine for patients with FTD, using the same rating scales that had been used previously in the DLB trial (Clinical Global Impression of Change and Neuropsychiatric Inventory). In fact, some of the patients with FTD developed worsening of their behavioral symptoms with memantine. Cholinesterase inhibitors, such as donepezil, also appear to cause behavioral deterioration in patients with FTD, according to some authors. ${ }^{28}$

A recent British study was designed to compare withdrawal of donepezil vs memantine in patients with moderate to severe $\mathrm{AD}$ to see whether either of these drugs was more or less effective in preventing nursing home placement. ${ }^{29}$ In a clinical trial involving 295 participants, the authors learned that withdrawal of donepezil significantly increased the risk of nursing home placement during the first 12 months of the study, but not in the following 3 years. In a prospective cohort study, patients with $\mathrm{AD}$ who were treated with donepezil appeared to have less progression of hippocampal atrophy over a year's time than those not treated with that drug. ${ }^{30}$ A recent clinical trial showed a $45 \%$ reduction in the rate of hippocampal atrophy with donepezil among 216 patients with prodromal $\mathrm{AD}$ who were randomly assigned to either donepezil or placebo for 1 year. ${ }^{31}$ These results suggest a neuroprotective effect of donepezil. 


\section{REFERENCES}

1. White LR, Edland SD, Hemmy LS, et al. Neuropathologic comorbidity and cognitive impairment in the Nun and Honolulu Aging Studies. Neurology 2016;86:1000-1008.

2. Musiek ES, Holzman DM. Three dimensions of the amyloid hypothesis. Nat Neurosci 2015;18: 800-806.

3. Insel PS, Mattsson N, Macklin RS, et al. Accelerating rates of cognitive decline and imaging markers associated with beta-amyloid pathology. Neurology 2016;86:1887-1896.

4. Prestia A, Caroli A, van der Flier WM, et al. Prediction of dementia in MCI patients based on core diagnostic markers for Alzheimer disease. Neurology 2013;80:1048-1056.

5. Galluzzi S, Marizzoni M, Babiloni C, et al. Clinical and biomarker profiling of prodromal Alzheimer's disease in workpackage 5 of the Innovative Medicines Initiative PharmaCog Project: a "European ADNI Study." J Intern Med 2016;279:576-591.

6. Jonsson T, Steffansson H, Steinberg S, et al. Variant of TREM2 associated with risk of Alzheimer's disease. N Engl J Med 2013;368:107-116.

7. DiFede G, Catania M, Morbin M, et al. A recessive mutation in the APP gene with dominantnegative effect on amyloidogenesis. Science 2009;323:1473-1477.

8. Jonsson T, Atwal JK, Steinberg S, et al. A mutation in APP protects against Alzheimer's disease and age-related cognitive decline. Nature 2012;488:96-99.

9. Vassar R, Kuhn PH, Haass C, et al. Function, therapeutic potential and cell biology of BACE proteases: current status and future prospects. J Neurochem 2014;130:4-28.

10. Rabinovici GD, Rosen HJ, Alkalay A, et al. Amyloid vs FDG-PET in the differential diagnosis of AD and FTLD. Neurology 2011;77:2034-2042.

11. Jack CR, Wiste HJ, Weigand SD, et al. Age, sex, and APO-E4 effects on memory, brain structure and beta-amyloid across the adult life span. JAMA Neurol 2015;72:511-519.

12. Noh Y, Jenn S, Lee JM, et al. Anatomical heterogeneity of Alzheimer disease. Neurology 2014;83: 1936-1944.

13. Mayeux R, Ottman R, Maestre G, et al. Synergistic effects of traumatic head injury and apolipoprotein-e4 in patients with Alzheimer's disease. Neurology 1995;45:555-557.

14. Mehta KM, Ott A, Kalijn S, et al. Head trauma and risk of dementia and Alzheimer's disease: the Rotterdam study. Neurology 1999;53:1959-1962.

15. Barnes DE, Kaup A, Kirby KA, et al. Traumatic brain injury and risk of dementia in older veterans. Neurology 2014;83:312-319.

16. Omalu B, DeKosky ST, Minster RL, et al. Chronic traumatic encephalopathy in a National Football League player. Neurosurgery 2005;57:128-134.

17. McKee A, Cantu RC, Nowinski CJ, et al. Chronic traumatic encephalopathy in athletes: progressive tauopathy following repetitive head injury. J Neuropath Exp Neurol 2009;68:709-735.

18. Stein TD, Montenigro PH, Alvarez VE, et al. Beta-amyloid deposition in chronic traumatic encephalopathy. Acta Neuropathol 2015;130:21-34.

19. Singh R, Meier TB, Kuplicki R, et al. Relationship of collegiate football experience and concussion with hippocampal volume and cognitive outcomes. JAMA 2014;311:1883-1888.

20. Buchman AS, Boyle PA, Yu L, et al. Total daily physical activity and the risk of AD and cognitive decline in older adults. Neurology 2012;78:1323-1329.

21. Verdelho A, Madureira S, Ferro JM, et al. Physical activity prevents progression for cognitive impairment and vascular dementia: results from the LADIS (Leukoaraiosis and Disability) Study. Stroke 2012;43:3331-3335.

22. Willey JZ, Gardener H, Caunca MR, et al. Leisure-time physical activity associates with cognitive decline: the Northern Manhattan Study. Neurology 2016;86:1897-1903.

23. Ngandu T, Lehtisalo J, Solomon A, et al. A 2-year multi-domain intervention of diet, exercise, cognitive training, and vascular monitoring versus control to prevent cognitive decline in at-risk elderly people (FINGER). Lancet 2015;385:2255-2263.

24. Smyth A, Dehghan M, O’Donnell M, et al. Healthy eating and reduced risk of cognitive decline. Neurology 2015;84:2258-2265.

25. Querforth HE, Laferla FM. Alzheimer's disease. N Engl J Med 2010;362:329-344.

26. Emre M, Tsolaki M, Bonucelli U, et al. Memantine for patients with Parkinson's disease dementia or dementia with Lewy bodies: a randomized, double-blind, placebo-controlled trial. Lancet Neurol 2010;9:969-977.

27. Boxer AL, Knopman DS, Kaufer DJ, et al. Memantine in patients with frontotemporal lobar degeneration: a multicenter, randomized, double-blind, placebo-controlled trial. Lancet Neurol 2013;2:S1474-S4422.

28. Mendez MF, Shapira JS, McMurray A, Lich E. Preliminary findings: behavioral worsening on donepezil in patients with frontotemporal dementia. Am J Ger Psychiatry 2007;15:84-87. 
29. Howard R, McShane R, Lindesay J, et al. Nursing home placement in the Donepezil and Memantine in Moderate to Severe Alzheimer's Disease (DOMINO-AD) trial: secondary and post-hoc analysis. Lancet Neurol 2015;14:1171-1181.

30. Hashimoto M, Kazui H, Matsumoto K, et al. Does donepezil treatment slow the progression of hippocampal atrophy in patients with Alzheimer's disease? Am J Psychiatry 2005;162:676-682.

31. Dubois B, Chupin M, Hampel H, et al. Donepezil decreases annual rate of hippocampal atrophy in suspected prodromal Alzheimer disease. Alzheimers Dement 2015;11:1041-1049.

Received June 19, 2016. Accepted in final form July 25, 2016.

\section{AUTHOR CONTRIBUTIONS}

F. Deak: prepared the first draft of the genetics section, including table 1; conceptualization; revising the manuscript. N. Kapoor: prepared the first draft of the neuroimaging section. C. Prodan: prepared the first draft of the trauma section, conceptualization, revising the manuscript. L.A. Hershey: prepared the first draft of the summary, healthy eating section, and cholinesterase inhibitor section; conceptualization; preparing the final revision of the manuscript.

\section{STUDY FUNDING}

No targeted funding reported.

\section{DISCLOSURES}

F. Deak serves as an Associate Editor of $A G E$ and receives research support from Oklahoma Center for the Advancement of Science and Technology and Presbyterian Health Foundation. N. Kapoor reports no disclosures. C. Prodin receives research support from the US Department of Veterans Affairs and Presbyterian Health Foundation. L. Hershey has served on the editorial boards of Neurology ${ }^{\circledR}$ and JSM Alzheimer's Disease \& Related Dementia; has received publishing royalties from MedLink and MedLink Neurology; receives/has received research support from Baxter, Forum Pharmaceuticals, NIH, University of Oklahoma Health Sciences Center, Alzheimer's Association, OU College of Nursing Grant, OU Norman Faculty Investment Grant, OU VP for Research Grant, and OUHSC Presbyterian Health Foundation Grant; and has given expert testimony in legal proceedings. Full disclosure form information provided by the authors is available with the full text of this article at Neurology.org/cp.

\section{Related articles from AAN physician and patient resources}

\section{Neurology ${ }^{\circledR} \quad$ Neurology.org}

Mechanisms of memory impairment in epilepsy depend on age at disease onset October 18, 2016;87:1642-1649.

Memory and Mechanism

September 29, 2015;85:1180.

Predicting memory change after temporal lobectomy for epilepsy

April 14, 2015;84:1508-1509.

\section{Neurology Now ${ }^{\circledR} \quad$ Neurologynow.com}

The Alzheimer's Café: In memory cafés popping up around the country, people with dementia and their caregivers can socialize without fear of stigma August/September 2016;12:8-9.

Protect Your Memory: New evidence suggests that healthy living may help preserve brain power October/November 2015;11:16-17.

\section{Neurology Today ${ }^{\circledR} \quad$ - Neurotodayonline.com}

Researchers Hone Use of fMRI to Predict Memory Loss After Epilepsy Surgery April 2, 2015;15:1,8-10. 